International Journal on Applied Bioengineering, Vol. 4, No.2, July 2010

\title{
ANTIBACTERIAL ACTIVITY AND GC MS ANALYSIS OF SECONDARY METABOLITES PRODUCED BY THE MANGROVE PLANT RHIZOPHORA MUCRONATA AGAINST MRSA
}

\author{
Elsa Lycias Joel ${ }^{1}$ and B. Valentin Bhimba ${ }^{2}$ \\ ${ }^{1}$ Institute for Environmental Research and Social Education (IERSE) \\ Nagercoil, Kanyakumari District. \\ ${ }^{2}$ Department of Biotechnology, Sathyabama University \\ Rajiv Gandhi Salai, Chennai-119. \\ Email: ${ }^{1}$ elsalyciasjoel@gmail.com
}

\section{Abstract}

Mangroves that need no introduction in today's world with a variety of bioactive metabolites have been the interest of marine researchers all over the world. Apart from the resources those flourishes in the dense tangle of roots, mud and tidal water, mangroves are known for it's medicinal wealth that have been successfully employed for treating a variety of diseases over hundreds of years. For generations, the mangroves have proven its use worldwide. The specific medicinal properties of Rhizophora mucronata depend on the part employed and finds its use to treat human ailments like angina, dysentery, hematuria and many more. It's no news that the mangrove microbial communities produce a plethora of bioactive secondary metabolites drawing many a curious researcher to the tidal swamps. The search for bioactive metabolites is a result of curiosity and interest as they prove to be new lead structures as generation next medicines bypassing the age-old antibiotics. The present study tests the foliar extracts of Rhizophora mucronata for its antibacterial effect. Moreover the mangrove ecosystem still remains a largely unexplored source of metabolites combating (Methicillin Resistant Staphylococcos aureus (MRSA) which consequently leads to studies that are underway to find natural remedies that can effectively take on MRSA .GC MS instrumental analysis was also done to identify the compound hitherto unprecedented in nature.

Keywords: Mangrove, Rhizophora mucronata, MRSA

\section{INTRODUCTION}

Mangroves, known for its rich variety of flora and fauna contain substances of medicinal value that are extracted from almost every part of it. Mangroves as such gained prominence after the tsunami of December 2004. Given its unique physical environment mangroves have evolved a suite of adaptations to cope with extreme environmental conditions that include high salinity, strong winds, tidal variations, high temperature and anaerobic tidal swamps. As per the volumes of available data, we need to understand that the mangrove ecosystem encompasses vast number of species that are a rich source of bioactive metabolites and enzymes. Though it is believed to be used only in alternative and complimentary medicine, the secondary metabolites against MRSA promises mainstream use too. Hence similar research will end in results that will prove the metabolites appropriate in all cases providing excellent remedies for infections caused by antibiotic resistant strains of microbes.
Approximately 55 species of mangroves from 22 genera are distributed in Indian Ocean region (Kathiresan and Rajendran, 2005). As much as the habitat of mangrove plants takes different names as mangrove swamps, tidal forests, tidal swamp forests or mangals, so are evidences for its antibacterial (Chandrasekaran et al., 2009), antiviral (Premanathan et al.,1999), Antifungal (Bose and Bose, 2008), mosquito larvicidal (Thangam and Kathiresan, 1989) and antioxidant activity (Babu et al., 2001).

In light of this, the present study was initiated to investigate the leaf extracts of Rizophora mucronata collected from Parangipettai, chidambaram district for its biological activity against certain bacteria that play havoc on human health like MRSA, infections of which aren't always very serious but at times are life threatening. Public health experts are alarmed by the spread of tough strains of MRSA, the 'super bug'. With the constantly adapting MRSA and infections becoming increasingly difficult to treat with antibiotics, research on natural alternatives is an exciting area of study. 


\section{MATERIALS AND METHODS}

\section{A. Collection and extraction of mangrove bioactive}

Leaves of Rhizophora mucronata were collected from mangrove forest of parangipettai, chidambaram located in Tamilnadu. Prior to the extraction, the leaves of respective species were washed with sterile water to remove any associated debris., shade dried in order to prevent photolysis and thermal degradation, chopped into small pieces and ground coarsely to powder form in a mechanical grinder.

For extraction of crude bioactives, $50 \mathrm{~g}$ of powered mangrove material was exhaustively extracted with $200 \mathrm{ml}$ of various solvents like ethanol, petroleum ether, acetone, methanol and ethyl acetate using soxhlet apparatus. The extracts are further concentrated by recovering excess solvents to a thick oily natured crude in a rotary evaporator at reduced pressure. The extract was stored at $4^{\circ} \mathrm{C}$ in air- tight plastic vials for further studies.

\section{B. Antibacterial assay}

Antibacterial activity was carried out against gram positive bacterium (Methicillin Resistant Staphylococcus aureus) by agar well diffusion method. The assay system was prepared with gel punctured Muller Hinton Agar plates. Test culture was swabbed aseptically and inoculated on the surface of the Muller Hinton Agar so as to make a lawn and left to dry for the wells to be perfect. For leaves and mycelium 1gm of the sample is dissolved in $1 \mathrm{ml}$ of the solvent and $1 \mathrm{ml}$ of filtrate is mixed with $1 \mathrm{ml}$ of the solvent from which various (15 $\mu \mathrm{l}, 25 \mu \mathrm{l}, 50 \mu \mathrm{l} /$ well) concentrations were taken and loaded in the well using micropipette and one well was loaded with the respective solvent as control. Plates were incubated for 16 to $18 \mathrm{hrs}$ at $37^{\circ} \mathrm{C}$ The percentage of mortality was determined by observing the zones of inhibition.

\section{Column chromatographic analysis of active foliar extracts}

The ethyl acetate extract of Rhizophora mucronata (1 gm) was loaded on a silica gel column packed with hexane and eluted with hexane and chloroform ( $9: 1$ to $1: 9$ \& $100 \%$ chloroform) followed by ethyl acetate and methanol $((9: 1$ to $1: 9$ \& $100 \%$ methanol) to yield 26 fractions. Individual fractions when collected and tested revealed that the $24^{\text {th }}$ fraction that was eluted using ethyl acetate and methanol (8:2) had maximum activity.

\section{UV Visible and GC MS spectral Analysis}

The absorbance of the fractions eluted from the column chromatography was measured at a resolution from 200- 800nm using UV-Visible spectrophotometer and the readings were recorded. The fractions that were eluted in column chromatography using chloroform and ethyl acetate (2:8) exhibiting activity was subjected to GC-MS equipped with Agilent 5975 inert XL MSD to find out the active principle of the extracts.

\section{RESULTS AND DISCUSSION}

The plant material was subjected to an extraction process with solvents like ethanol, petroleum ether, acetone, methanol and ethyl acetate. The crude ethyl acetate extracts $(50 \mu \mathrm{l})$ of $R$. mucronata showed remarkable antibacterial activity with zones of inhibition of $28 \mathrm{~mm}$ against MRSA (Plate 1 and Table 1 ). The test organisms were based on the choice of their ubiquitous presence. Staphylococcus aureus has its notorious reputation for causing cellulites, boils, impetigo and scalded skin syndrome. The best of diagnosis, clinicians and treatment fail to treat the affected, as th e antibiotic resistance in some strains are on the rise. This study also provides us hope to overcome failures of drug resistance by development of new drugs. Some of the phytochemical compounds e.g. glycoside, saponin, tannin, flavonoids, terpenoids, alkaloids, have variously been reported to have antimicrobial activity (Okeke el al., 2001; Ebi and Ofoefule et al., 1997). The studies of Powar \& Pratishtha et al., 2009 that included screening the methanolic extracts of barks of eight mangrove species for antibacterial activity against Bacillus megateriumn and Staphylococcus aureus did prompt us to study the leaf extracts for antibacterial effects.

\section{Table 1. Antibacterial activity of Rhizophora mucronata against MRSA}

\begin{tabular}{|c|l|c|c|c|}
\hline \multirow{2}{*}{ S.No } & \multicolumn{1}{|c|}{ Extracts } & \multicolumn{3}{|c|}{$\begin{array}{c}\text { Zone of inhibition } \\
\text { (mm) }\end{array}$} \\
\cline { 3 - 5 } & & $15 \mu \mathrm{l}$ & $25 \mu \mathrm{l}$ & $50 \mu \mathrm{l}$ \\
\hline 1. & Crude extract & 8 & 11 & 15 \\
\hline 2. & $\begin{array}{l}\text { Eluted fraction from } \\
\text { Colum }\end{array}$ & 9 & 12 & 18 \\
\hline
\end{tabular}




\section{Plate 1 Zone of Inhibition on Muller Hinton Agar at different concentration}
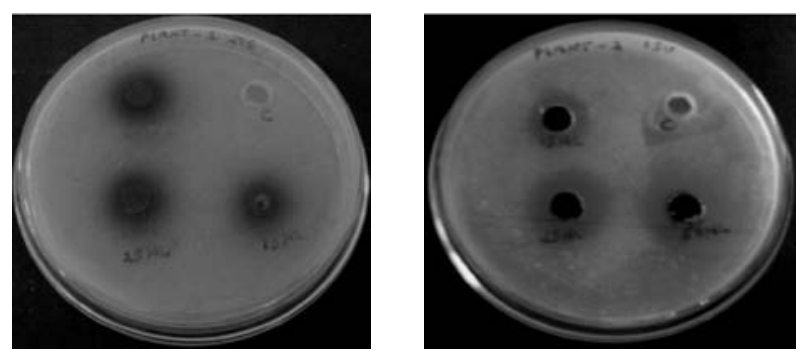

Crude extract Column eluted fraction

Bioactivity guided fractionation is another best method to seek the active compound by separating mixture compounds from targeting extracts. Elution of individual fractions of foliar extracts of $R$. mucronata by column chromatography and their absorbance at 200 to $300 \mathrm{~nm}$ in a UV visible spectrum revealed fraction 24 (ethyl acetate: methanol 8:2) as the most potent one against with the MIC of $15 \mathrm{~nm}$ against $S$. aureus (Plate 1 and Table 1).

The GC MS results (Fig.1) of active column fraction (F24) revealed that the active principals were a mixture of squalene (19.19\%), n-Hexadecanoic acid (6.59\%), phytol (4.74\%), 2-cyclohexane-1- one, 4-hydroxy-3,5, (4.20\%) and oleic acid (2.88\%). Recent research also reports that many fatty acids from mangroves posses antimicrobial property (40 to 43 ).

Fig. 1. GC MS analysis of Rhizophora mucronata

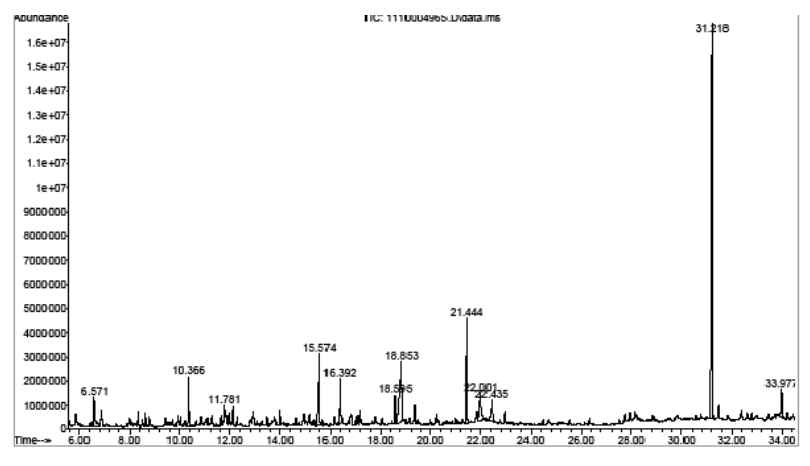

While taking this study to another level of finding solutions to antibiotic resistant pathogenic microorganisms is a high probability, there are enough studies on the antibacterial activity of aqueous and methanol extracts of leaves / shoots of five salt marsh halophytes and six mangroves against methicillin resistant clinical isolates of Staphylococcus aureus (Chandrasekaran et al., 2009). Natarajan Suganthy et al. (2009) studied the antibacterial activity of methanolic leaf extracts of mangrove plants collected from Pichavaram and Thondi.

Future extension of this study includes bio assay against human cell lines especially cancer cells. Jones et al., 2005 reported 3 chlordeoxylapachol; a 20 metabolite obtained from the chloroform extract of mangrove tree was active against $\mathrm{K} B$ Human cancer cells in the murine hallow fibre antitumour model.

\section{CONCLUSION}

The foliar extracts of $R$. mucronata were studied for bioactivity against $E$. coli and $S$. aureus. The preliminary screening of crude extracts showed some biological activity against E.coli and S.aureus. A column chromatographic fractionation of the extracts and further UV visible and GS MS analysis suggested the active principle compound. Research of this kind will pave way for the community of drug developers too. The results do have immediate goals if further perusal with a larger motive is carried out. The leaf extracts with proven antibacterial effects can clearly be directed towards cancer treatment as to inhibiting cancer cell growth. The limited number of test organisms owes to a constraint of resource. So, the effect of strong bursts of leaf extracts on human pathogenic bacteria should further be tested on a wide range of test organisms. This study also means a natural alternative to antibiotics, which is an exciting and potentially extreme area of research.

\section{REFERENCES}

[1] Babu, B.H., B.S. Shylesh, J. Padikkala, 2001. Antioxidant and hepatoprotective effect of Acanthus ilcifolius. Fitoterapia 72: 272 to 277.

[2] Bose, S and A. Bose, 2008. Antimicrobial activity of Acanthus ilcifolius (L). Indian Journal of Pharmacy Science, 70:821- 3.

[3] Chandrasekaran, M., K. Kannathasan, V.Venkatesalu and K. Prabhakar, 2009, Antibacterial activity of some salt marsh halophytes and mangrove plants against methicillin resistant Staphylococcus aureus World Journal Microbiology and Biotechnology, 25: 155 to 160.

[4] Ebi, G.C., and S.I. Ofoefule,1997. Investigation into the Folkloric Antimicrobial Activities of Landolphia owariensis. Phytother. Res.,11(2): 149-151.

[5] Jones, P. William, Lobo Echeverri Tatiana, Mi Qiuwen, Chai, Heebyung, Lee Dongho, D. Soejarto Daja., A. 
Geoffrey, M.D.John, Swanson, M. Steeven and K.A. Douglas, 2005., Antitumor activity of 3 Chlorodeoxylapachol a naphthoquinone from Avicennia germinans collected from an experimental plot in southern Florida Journal of Pharmacy and pharmacology, 57(9): 1101-1108.

[6] Kathiresan, $\mathrm{K}$ and N. Rajendran, 2005. Mangrove ecosystems of Indian Ocean, Indian Journal of marine sciences, 34(1): 104 to 113.

[7] Natarajan Suganthy, Periyanaina Kesika, Shanmugaiahthevar Karutha Pandian, Kasi Pandima Devi, 2009. Mangrove Plant Extracts: Radical Scavenging Activity and the Battle against Food-Borne Pathogens. Forsch Komplementmed , 16:41-48.

[8] Okeke, M.I., C.U. Iroegbu, E.N. Eze, A.S. Okoli, and C.O. Esimone, 2001. Evaluation of extracts the roots of Landolphia owerrience for antibacterial activity. J. Ethanopharmacol., 78: 119-127.

[9] Powar Pratishtha S., Gaikwad D. K., and P.D.Chavan, 2009. Antibacterial activity of Mangrove bark. BIOINFOLET - A Quarterly Journal of Life Sciences, Vol 6(4):

[10] Premanathan, M., R. Arakaki, H. Izumi, K. Kathiresan, M.Nakano and N.Yamamoto, 1999. Antiviral properties of a mangrove plant, Rhizophora apiculata blume against human immunodeficiency virus. Antiviral Research, 44:113 to 122.

[11] Thangam, T.S. and K. Kathiresan, 1989. Larvicidal effect of marine plant extracts on mosquito Culex tritaeniorhynchus. Journal of the Marine Biological Association of India, 31: 306 to 307. 